\title{
Productivity benefits of industrial energy efficiency measures
}

\author{
Ernst Worrell, ${ }^{-\underline{a}}$, John A. Laitner ${ }^{\underline{\mathbf{b}}}$, Michael Ruth ${ }^{\underline{\mathbf{a}}}$ and Hodayah Finman $\underline{\mathbf{b}}$ \\ ${ }^{a}$ Energy Analysis Department, Lawrence Berkeley National Laboratory, \\ MS: 90R4000, 1 Cyclotron Road, Berkeley, CA 94720, USA \\ ${ }^{\mathrm{b}}$ US Environmental Protection Agency, \\ MS: 6201J, 1200 Pennsylvania Ave, NW, \\ Washington, DC 20460, USA
}

4 December 2001.

\begin{abstract}
We review the relationship between energy efficiency improvement measures and productivity in industry. We review over 70 industrial case studies from widely available published databases, followed by an analysis of the representation of productivity benefits in energy modeling. We propose a method to include productivity benefits in the economic assessment of the potential for energy efficiency improvement. The case-study review suggests that energy efficiency investments can provide a significant boost to overall productivity within industry. If this relationship holds, the description of energy-efficient technologies as opportunities for larger productivity improvements has significant implications for conventional economic assessments. The paper explores the implications this change in perspective on the evaluation of energy-efficient technologies for a study of the iron and steel industry in the US. This examination shows that including productivity benefits explicitly in the modeling parameters would double the cost-effective potential for energy efficiency improvement, compared to an analysis excluding those benefits. We provide suggestions for future research in this important area.
\end{abstract}

\section{Table of Contents}

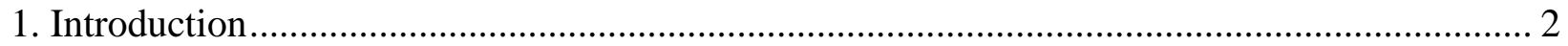

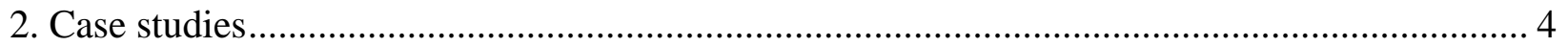

3. Integrating productivity in energy efficiency analysis.................................................... 7

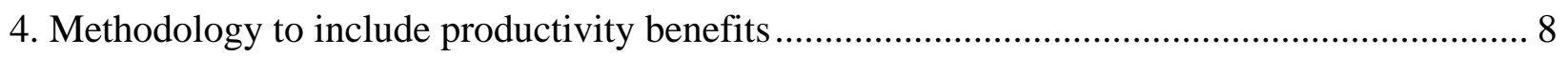

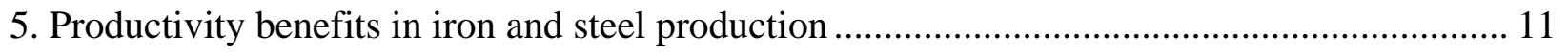

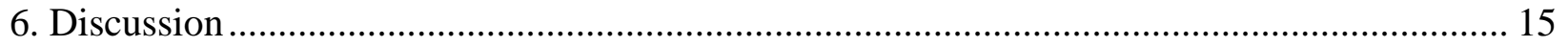

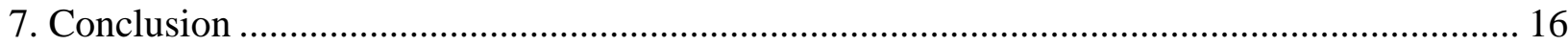




\section{Introduction}

Research and development efforts across all industries are driven by the goal of improving the productivity of industrial processes. Improvements can come in a variety of ways, including lower capital costs and operating costs, increased yields, and reductions in resource and energy use. Any industrial technology development will incorporate one or more of these improvements. Some innovations may primarily be aimed at one goal, but also generally include beneficial impacts on other aspects of a production process.

Certain technologies that are identified as being 'energy-efficient' because they reduce the use of energy will bring a number of additional enhancements to the production process. These improvements, including lower maintenance costs, increased production yield, safer working conditions, and many others, are collectively referred to as 'productivity benefits' or 'non-energy benefits' (or NEBS) ${ }^{[1]}$, because in addition to reducing energy, they all increase the productivity of the firm. In general, productivity expresses a relationship between the quantity of goods and services produced by a business or an economy and the quantity of labor, capital, energy, and other resources that are needed to produce those goods and services. Several authors have studied the relationship between productivity and energy efficiency and found a direct relationship using different methodologies and datasets ${ }^{[2,3 \text { and } 4]}$.

In this study, we focus on modeling the impact of productivity increases on the costeffectiveness and economic evaluation of energy-efficiency measures and technologies. We also focus on the industrial sector. Mills and Rosenfeld ${ }^{[1]}$ studied the role of 'additional benefits' for building energy efficiency measures, and provide a framework for understanding the many benefits of energy efficiency investments that extend beyond the energy bill savings alone. Although they recognize the national benefits (e.g., improved competitiveness, energy security, net job creation, and environmental protection) as important, the authors provide a detailed description of user benefits made possible by efficiency technologies. The full set of non-energy benefits reflect: (1) improved indoor environment, (2) noise reduction, (3) labor and time savings, (4) improved process control, (5) increased amenity or convenience, (6) water savings and waste minimization, and (7) direct and indirect economic benefits from downsizing or elimination of equipment. Mills and Rosenfeld ${ }^{[1]}$ note that these non-energy benefits play a key role in consumer decision-making. As a result, efforts to incorporate them in program design and marketing will help accelerate the uptake of energy-efficient technologies.

Focusing on the productivity benefits discussed in the industrial case studies reviewed below, we identified five broad categories or common themes, including (not in order of importance): reduced waste, lower emissions, improved maintenance and operating costs, increased production and product quality, and an improved working environment. We have also included an 'other' category to identify those benefits that were outside the other categories, but still worthy of noting (see Table 1). 
Table 1. Non-energy benefits from efficiency improvements

\begin{tabular}{|c|c|c|}
\hline Waste & Emissions & Operation and maintenance \\
\hline $\begin{array}{l}\text { Use of waste fuels, heat, gas } \\
\text { Reduce product waste } \\
\text { Reduce waste water } \\
\text { Reduce hazardous waste } \\
\text { Materials reduction }\end{array}$ & $\begin{array}{l}\text { Reduced dust emissions } \\
\text { Reduced CO, CO2, NOx, SOx } \\
\text { emissions }\end{array}$ & $\begin{array}{l}\text { Reduced need for engineering } \\
\quad \text { controls } \\
\text { Lowered cooling requirements } \\
\text { Increased facility reliability } \\
\text { Reduced wear and tear on } \\
\text { equipment/machinery } \\
\text { Reductions in labor requirements }\end{array}$ \\
\hline Production & Working environment & Other \\
\hline $\begin{array}{l}\text { Increased product } \\
\text { output/yields } \\
\text { Improved equipment } \\
\text { performance } \\
\text { Shorter process cycle times } \\
\text { Improved product } \\
\text { quality/purity } \\
\text { Increased reliability in } \\
\text { production }\end{array}$ & $\begin{array}{l}\text { Reduced need for personal } \\
\text { protective equipment } \\
\text { Improved lighting } \\
\text { Reduced noise levels } \\
\text { Improved temperature control } \\
\text { Improved air quality }\end{array}$ & $\begin{array}{l}\text { Decreased liability } \\
\text { Improved public image } \\
\text { Delaying or Reducing capital } \\
\quad \text { expenditures } \\
\text { Additional space } \\
\text { Improved worker morale }\end{array}$ \\
\hline
\end{tabular}

Understanding these benefits and properly incorporating them into cost analyses is important because these improvements can significantly change the cost assessment of the technology and result in a more favorable evaluation. At the project level, the effect of productivity benefits on cost assessments could determine whether or not a project is undertaken. From a macroperspective, the evaluation of productivity benefits will influence the assessment of the energyefficiency potential. Industry and sectoral modeling studies often exclude an (explicit) evaluation of the productivity benefits in assessments of the potential for energy-efficiency improvement (see below).

This paper focuses on the role of productivity benefits in assessing total energy-efficiency potential across an entire industry. At the industry-wide level, it is important to distinguish between the total technical potential for energy savings and the cost-effective potential. The former describes what energy savings could be attained given current state-of-the-art technology, regardless of cost, while the latter requires a cost analysis to see what savings could be costeffectively or economically achieved. The cost-effective potential is affected by productivity benefits. Still, productivity benefits are often not quantified or included in most studies of energy-efficiency potential. In general, this omission of productivity benefits results in an underestimation of the cost-effective savings potential. A methodology is needed that incorporates the productivity benefits of energy-efficiency technologies into assessments of energy savings potential in a systematic quantified way.

Ideally it would be useful to have access to time series data comparing changes in capital and energy consumption with other changes in other production inputs such as labor, materials, and services. Presumably, the larger multifactor productivity gains from purely energy efficiency investments would emerge in the relevant data. Unfortunately, such time series data that captures all appropriate inputs does not exist. For that reason, this paper proposes a methodology using conservation supply curves to quantify the potential productivity benefits from energy efficiency investments and incorporate them into energy-efficiency analysis. First, we start with an overview of many case studies that explicitly assessed productivity impacts of an energy 
efficiency measure. While this may produce a bias in our analysis since the results from less successful or even unsuccessful projects are unlikely to be published, the depth of the information suggests a pronounced trend that has not been adequately reflected in past studies of energy efficiency potential. Following the review of the case studies, we define our terminology and outline a method to estimate productivity impacts in the absence of more detailed time series data. We present an example of the methodology using data developed in an assessment of energy-savings potential in the US iron and steel industry. Finally, we discuss the methodology and some issues that arise in applying it, and we end with conclusions and recommendations for future research and policy needs.

\section{Case studies}

Much of the information on productivity benefits of energy conservation projects comes from two sources: articles on projects from trade literature and case studies on demonstration projects or government-funded projects. Pye and McKane ${ }^{[5]}$ analyzed a set of projects undertaken through the Department of Energy's Motor Challenge Program to explore how energy efficiency projects increase shareholder value. They found that new motors led to better operations of entire systems, reducing wear and tear and extending the lifetime of system components. The reduced capital expenditures and labor costs that resulted were larger than the energy savings in every case they analyzed. Lilly and Pearson ${ }^{[6]}$ analyzed another set of industrial projects where the energy conservation components added through the project helped to 'streamline' the production process, leading to lower maintenance costs and replacement costs of related components. For a cement plant they analyzed an efficient milling system led to more uniform raw material, which allowed the kiln to operate at lower temperatures with increased stability. This led to decreased emissions of $\mathrm{SO}_{2}$ and $\mathrm{NO}_{\mathrm{x}}$, the former of which is regulated in the region where the plant operates, so fines were avoided.

In order to gain an overview of the costs and benefits of a wide variety of energy efficiency upgrades, we identified a total of 77 case studies with sufficiently documented non-energy benefits. The projects were drawn from examples in six countries from the Organisation for Economic Development (OECD). They included the full spectrum of manufacturing activities. However, only 52 had sufficient data to quantify or assign a monetary value to some portion of the reported non-energy benefits. These case studies were drawn from reports or studies from the American Council for an Energy Efficient Economy ${ }^{[7}$ and 8$]$, IEA/CADDET database ${ }^{[9]}$, the US Environmental Protection Agency's Climate Wise case study compendium [10], the US

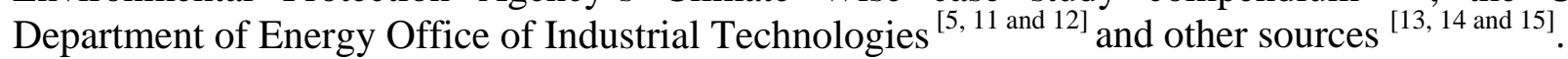

The case study data were entered into an Excel workbook. Each case study was assigned a project number with relevant data for each case study entered in the workbook. Among the typical data entries was information such as project cost, energy savings, non-energy savings when applicable, the 'energy only' payback, and payback associated with total project savings. All costs and prices were converted to US 1997 dollars. All energy prices and savings were evaluated on the basis of US average energy costs. A separate set of spreadsheets enumerating the non-energy benefits were compiled for the monetized and non-monetized case studies.

For case studies that quantified non-energy benefits but did not assign a monetary value to those savings, we generated an avoided cost estimate based upon published data found elsewhere in the literature. Energy savings were calculated on a fuel delivered basis rather than a primary energy basis. Conversion factors and calculations that were used in the analysis were documented within the workbook. 
A note of caution is warranted in that the compilation of case studies reported here does not comprise a statistically valid sample. In other words, the case studies were not selected at random and therefore are not necessarily representative of the universe of projects. In addition, the sample size of case studies is too small to be representative. Furthermore, the CADDET database reports on demonstration projects. This database may not contain failed demonstration projects, although the CADDET database does report on projects with unattractive economics. Even so, the data provide useful insights that might assist in the evaluation of energy technology investments.

A total of 52 case studies that monetized non-energy savings and an additional 25 case studies that qualitatively documented non-energy benefits are analyzed in this section. The assessment described here is based on the 52 monetized case studies only. Monetized non-energy savings are cost-savings quantified in the case study, although in some cases not all non-energy benefits would be captured quantitatively. Despite the small sample, it is clear that including the non-energy benefits of a project, and incorporating that information into the engineering analysis when making a decision about a capital upgrade, may have a profound effect upon decisionmaking process of a given project. A look at the 52 monetized case studies reveals a $4.2 \mathrm{yr}$ payback based only on the energy savings (Table 2). This falls to a $1.9 \mathrm{yr}$ payback for projects when including the full productivity impacts of a project (i.e., dividing the total investment by both the energy savings and the non-energy benefits of a project). There is no discernable pattern in the frequency of projects based on standard industrial classification (SIC) code. Below is a breakdown of projects of the most frequently occurring SIC codes among the monetized case studies (Table 3).

Table 2. Monetized case study investments and paybacks

Total project investment

$\$ 54,179,060$

Total annual energy savings

$\$ 12,933,255$

Total annual productivity savings

$\$ 15,695,582$

Combined total savings

$\$ 28,493,331$

Average energy payback

$4.2 \mathrm{yr}$

Average payback including energy and non-energy benefits

$1.9 \mathrm{yr}$

Table 3. SIC code frequency among monetized case studies

\begin{tabular}{|c|c|c|}
\hline SIC code & Industry & Number of case studies \\
\hline 20 & Food manufacturing & 9 \\
32 & Building materials & 7 \\
33 & Steel manufacturing & 7 \\
26 & Paper manufacturing & 6 \\
28 & Chemicals manufacturing & 6 \\
23 & Textile manufacturing & 4 \\
\hline
\end{tabular}

The full set of 77 case studies that we surveyed fell into one of two broad categories: (a) conventional upgrades, or (b) state-of-the-art technologies. The less expensive projects usually involved conventional retrofits of existing equipment, often as a component of a more comprehensive project. The larger, more expensive projects generally involved new, state-of-theart equipment designs. The majority of case studies collected in the literature were of projects in 
the latter category with projects ranging from infrared dryers and new types of furnaces to improved burners. Forty-one out of the 77 case studies examined in this review were what we categorized as state-of-the-art projects while 35 dealt with more conventional retrofits.

The types of technologies installed were consistent with the critical manufacturing elements of the industries sampled in the case study literature. Out of the 77 case studies examined for this analysis, a significant number focused on energy savings from more efficient de-watering or water re-use. This category of projects included applications in the pulp and paper industry, food processing, industrial machinery, and textile manufacturing. Other installed technologies included motor replacements, fans/duct/pipe insulation, improved sensors and controls, and new state-of-the-art technology designs.

In analyzing the initial motivation behind a given project $39 \%$ of the 41 state-of-the-art projects cited the need to relieve a production bottleneck or increase productivity as one of the primary reasons for pursuing the project. In contrast, only $14 \%$ of 35 conventional technology projects cited increasing productivity as a primary objective. Once again, these findings are not statistically significant because of the limited case study universe available for this study and bias in the documentation. There seemed to be no discernable trend related to project motive and standard industrial classification code. Projects were not more likely to have been initiated to relieve a production bottleneck in any one SIC code over another, nor was there any obvious trend related to SIC code and the selection of a state-of-the- art versus a conventional project.

The state-of-the-art projects generally cost more to implement but had higher rates of returns when calculating all of the easily monetized non-energy benefits. The average cost of a state-ofthe-art project was 1.8 times the cost of the conventional project. The average annual total savings, including monetized non-energy benefits, for state-of-the-art projects was about 1.5 times greater than for conventional energy efficiency upgrades.

Of the 52 monetized case studies, the dollar ratio of savings from non-energy benefits to savings from energy efficiency ranged from 0.03 to over 70 , initially indicating a wide range of added value derived from the non-energy benefits. However, in $63 \%$ of the cases, the non-energy benefits were equal to or greater than the energy savings. In nearly $30 \%$ of these case studies the non-energy savings were three times more than the energy savings, and in about $25 \%$ of the cases, the non-energy savings were more than four times the energy savings.

Non-energy benefits clearly yield significant and positive results in these case studies. Some 224 different non-energy benefits were cited in the 77 case studies culled for this paper. The most common form of cost reduction observed under the heading of waste/materials reductions are reductions in materials (12 cases), followed by reductions in water used (five cases). The most common abatement of air pollutants among the case studies were reductions in $\mathrm{SO}_{2}, \mathrm{NO}_{\mathrm{x}}$ and $\mathrm{CO}_{2}$ from reduced on-site fuel and electricity consumption, followed by reductions in $\mathrm{CO}$, VOCs, and hydrocarbons. There were six cases of reduced dust emissions. The most common benefit cited in the improved maintenance and operation category was lower costs from reduced equipment wear and tear (20 cases). Reductions in required labor costs were noted in eight cases. Non-energy benefits categorized as other include reductions in noise (five cases), and improved worker morale (two cases).

The analysis of the case studies clearly demonstrates the importance of accounting of the productivity benefits in the assessment of a project and in the assessment of the potential for energy efficiency improvement. In the next section we evaluate different studies that have integrated the productivity benefits into the assessment of the energy efficiency improvement potential. 


\section{Integrating productivity in energy efficiency analysis}

The findings of the studies discussed in the previous section should help bolster the role of productivity benefits in promoting industrial energy efficiency projects. Ingram ${ }^{[16]}$ points out that early DSM projects presented to industry (specifically in the case by Bonneville Power Administration) intentionally avoided addressing productivity benefits and instead focused on maintaining the same processes and changing only existing equipment-e.g. lights and motors. The reasons for this focus were that production changes contained considerable risk for the investor. It is now clear that even without making process changes, productivity benefits can be reaped from energy efficiency investments.

While the case for productivity benefits is being made at the project level, there is still little incorporation of this information into sector- or country-wide analyses or into the engineeringeconomic models that are used to support these analyses. One problem is that these models often do not contain explicit information on specific technologies. Two models used in many studies of US energy forecasts are the Long-range Industrial Energy Forecasting (LIEF) model ${ }^{[17]}$ and the National Energy Modeling System (NEMS) ${ }^{[18]}$, neither of which includes specific equipment information. In LIEF, the relationship of energy prices to industry-wide energy consumption is described by parameters estimated from historical data; there are no specific choices regarding technologies. In NEMS, trends in energy use are determined exogenously and input to the model, so any potential impact from productivity benefits would need to be determined a priori. Another modeling framework is found in the ISTUM/ITEMS class ${ }^{[19]}$ of models, which have been used for national studies in the US and Canada. The ISTUM/ITEMS models use a detailed breakdown of industrial processes and allow for technology choice at each step. The technology choice methodology is based on life-cycle costs of the various options. This framework would allow for productivity benefits to be included in the cost calculations, although this is not part of the model currently.

Various international models do incorporate detailed information on individual technologies to assess the future potential for energy efficiency improvement and $\mathrm{CO}_{2}$ emission reduction. The MARKAL-model is used mainly in IEA countries and by many institutes. Although the model can handle a large number of technologies, the size of the technology database varies by institute and country. The MARKAL-model used in The Netherlands ${ }^{[20]}$ contains a large technology database, including industrial technologies (see e.g. ${ }^{[21]}$ for description of a selected set of input data for the MARKAL-MATTER model for Western-Europe). Industrial technologies are often modeled as alternative processes for existing processes. In most technology descriptions, changes in investment costs seem to be taken into account, while changes in operation costs for the different technologies were not found. This suggests that some of the productivity benefits may have been captured in the data, but that productivity analysis is not a separate part of the process data analysis. A study in The Netherlands that tried to assess the potential energy efficiency improvement in a bottom-up manner using supply curves for conserved energy is the ICARUS-model ${ }^{[22]}$. Although the study captured a few reductions in operation costs, most often operation costs increase compared to the technology already in place. The authors state that it was difficult to collect reliable data on changes in operation costs and hence effectively model the potential effects of productivity benefits. In Germany, the IKARUSproject ${ }^{[23]}$ has constructed a large database on energy-efficient industrial technologies, but has generally excluded data on changes in operation costs, not capturing productivity benefits. These examples suggest that often studies do not pay special attention to productivity benefits in the assessment of the economics of energy-efficiency improvement.

As awareness of and knowledge about productivity benefits increases through analysis at the project level, it will become impossible to ignore these benefits at the level of sector- or industry- 
wide analysis. With the deregulation of the electricity sector, utility sponsored energy-efficiency programs are in transition, and perhaps will disappear. At the same time, this deregulation could lead to lower electricity prices, removing an incentive for efficiency. In this climate, productivity benefits could become the driving force behind efficiency projects and programs, a path suggested by a recent report on California's energy efficiency programs ${ }^{[24]}$. Analysts need to better understand and include these benefits in order to make accurate forecasts of energy trends. The next section introduces a methodology for incorporating productivity benefits in assessments of energy efficiency potential.

\section{Methodology to include productivity benefits}

Since there is an increasing amount of information and data on productivity benefits but there is little application of these benefits in the creation of energy consumption scenarios, we need to develop a method for bringing productivity benefits into the integrated analysis. In this section we first discuss a method for identifying and assessing these benefits; then we introduce the use of conservation supply curves for incorporating the effects into assessments of the energyefficiency potential.

A framework for evaluating the productivity benefits of energy efficiency technologies is laid out in the steps below. This approach begins by asking broadly: aside from energy conservation, what impacts does this technology have on the production process? In order to incorporate these into an economic analysis, these impacts then need to be translated into economic terms wherever possible. This framework is useful for making the cost calculations and it makes the evaluation process transparent for the analyst.

1. Identify and describe the productivity benefits associated with a given measure. This involves listing all the significant impacts of a measure aside from energy savings. These benefits will fall into the general categories listed in section 2, but should be described as specifically as possible.

2. Quantify these impacts as much as possible. Here the benefits identified above should be quantified in the most direct terms possible. For example, if one benefit is the extended lifetime of electrodes in electric steelmaking, estimate the change in lifetime or the reduced electrode consumption per tonne of steel. A benefit may be deemed 'non-quantifiable'. For example, adopting a technology may enhance a firm’s reputation as an innovator and leader, but this is too intangible to quantify.

3. Identify all the assumptions needed to translate the benefits into cost impacts. The quantities identified above should be direct measures of benefits, but these may not be directly applicable to the production costs of the firm. Making this connection to production costs will require certain assumptions or intermediate values. For reductions in electrode consumption, the cost of electrodes is needed. Other assumptions may involve greater uncertainty.

4. Calculate cost impacts of productivity benefits. Relying on the assumptions listed in the above step, the magnitude of the productivity benefits can be calculated in cost terms. This cost value can now be incorporated into the cost calculation for the efficiency measure or technology.

By following the framework detailed above, the cost evaluation of productivity benefits is formalized and transparent. Since the evaluation of productivity benefits is not always unambiguous, the transparency of this evaluation framework is important both to give credibility to the calculation and to provide flexibility. 
Once productivity benefits have been evaluated in cost terms, an effective way of incorporating them into an energy scenario analysis is by using bottom-up energy conservation supply curves (CSCs). CSCs were developed in the 1970s as a means of ranking energy conservation investments alongside energy supply investments in order to assess the least cost approach to meeting energy service demands. In these curves, the amount of energy conserved is plotted against the cost of attaining this conservation, with costs expressed on a per energy unit basis. From another perspective, the CSC shows how much energy conservation would be 'supplied' under a given energy price.

The term 'bottom-up' is used to describe CSCs that are constructed starting from technology data and cost data for each energy-conserving technology or measure. For each measure, total conservation potential and the costs of conserving energy (CCE) can be determined from engineering principles. ${ }^{1}$ The CCE of a particular option is calculated as:

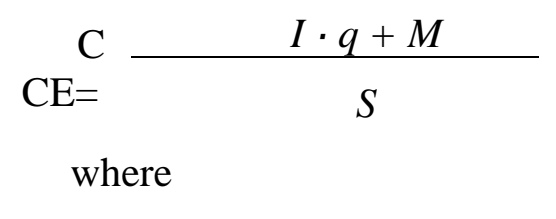

(2)

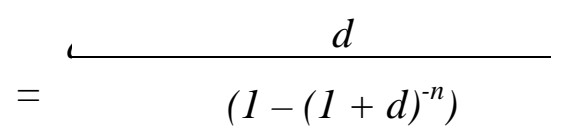

$\mathrm{CCE}=$ cost of conserved energy for the energy efficiency measure, in \$/GJ

$I=$ capital cost $(\$)$

$q=$ capital recovery factor

$M=$ annual change in O\&M costs (\$)

$S=$ annual energy savings (GJ)

$d=$ discount rate

$n=$ lifetime of the conservation measure (yr)

For most investments, including those in energy-efficient technologies, the bulk of the additional expenses occurs in the first year, while the benefits accumulate over a number of years after the investment. To make the cost and benefit streams comparable, capital costs are 'annualized' using a capital recovery factor, which takes into account the investor's discount rate and the lifetime of the investment. The CCE represents the sum of the annualized capital costs and the incremental operating and maintenance costs, divided by the annual energy savings.

By expressing the CCE on a per-energy-unit basis, it can be compared to the energy price. If the CCE of a given investment at a given discount rate is below the energy price, it is cheaper to make the investment in the energy-efficient technology and conserve energy than it would be to purchase the energy. To construct a CSC, CCEs can be calculated for each energy conservation measure and then ranked in order of increasing CCE. These can be plotted consecutively with cumulative energy savings along the $\mathrm{x}$-axis and CCE along the $\mathrm{y}$-axis. The point at which the curve crosses the price of energy gives the cost-effective energy savings potential. See Fig. 1 for an example from the iron and steel industry. 


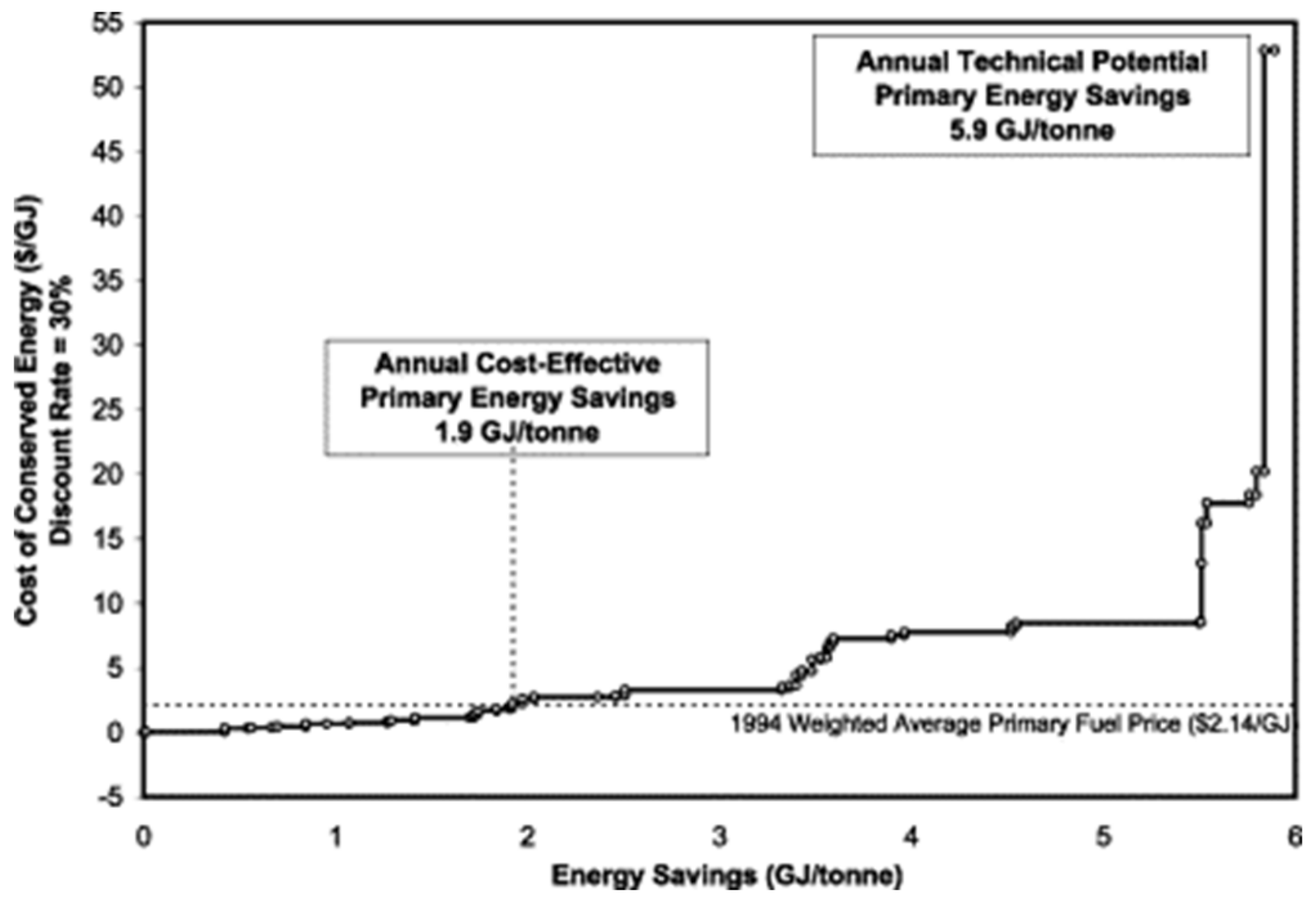

Fig. 1. Conservation supply curve for the iron and steel industry illustrating 47 conservation measures for both integrated and electric steelmaking, excluding productivity benefits.

Accounting for productivity benefits will offset some of the annual costs of an energy efficiency measure, thereby lowering the CCE. Adjusting the CCE calculation to account for productivity benefits would look like this:

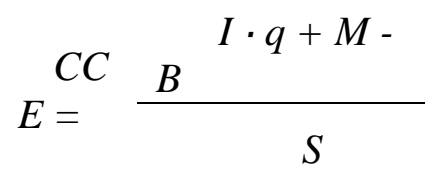

where $B=$ annual total of productivity benefits (\$)

Note that non-energy benefits may include reduced operation and maintenance, which would lead to a reduction in $M$, as well as reduced capital costs, which would lead to reduction in $I$. Once the productivity benefits have been included in the CCE, some measures will be more costeffective and the order of the measures in the CSC may be different from when no benefits were included. These changes will affect the CSC in two ways: there will be an overall downward shift in the curve and the shape of the curve may change. However, only the change in the 
magnitude of the cost-effective potential is of importance for the assessment of sector-wide assessments. The CSC does not provide sufficient information to determine a ranking of costeffectiveness of energy- efficiency improvement measures. Other measures of cost-effectiveness maybe needed, e.g. return on investment. The total technical potential for energy conservation will not change, but more measures may now have a CCE that falls below the threshold of energy price, so the cost-effective savings potential may be larger. In the next section data from the iron and steel industry are used to construct conservation supply curves that demonstrate the importance of productivity benefits.

\section{Productivity benefits in iron and steel production}

A recent study ${ }^{[25]}$ presents an opportunity to look at productivity benefits using conservation supply curves. This study constructed energy- conservation supply curves for the entire US iron and steel industry. Forty-seven commercially available energy efficiency measures are identified: 26 of these are specific to integrated steelmaking, 11 options pertain to electric steelmaking, and 10 measures apply to both integrated and electric processes. These efficiency measures are listed in Table 4.

The authors of the study estimated the total penetration of each measure and then calculated the conservation in terms of reductions of energy intensity for the industry as a whole. Energy intensity of steel production (SIC 331 and 332) in 1994 was approximately $26 \mathrm{GJ} / \mathrm{t}$, and the 47 measures identified could reduce the intensity by $5.9 \mathrm{GJ} / \mathrm{t}$. For all of the measures a cost of conserved energy was calculated that included information on investment costs, operation and maintenance costs, and energy costs and savings. In addition, productivity benefits were identified for 14 of the measures. If the CCE calculation were done without including the productivity benefits, following the Eq. (1) shown above, the 47 measures would give a CSC like the one shown in Fig. 1.

Excluding productivity benefits, the CCEs for the iron and steel measures range from $\$ 0 / G J$ (no incremental cost) to over $\$ 50 / G J$. The weighted average price of primary fuel used in the sector is indicated on the figure. The intersection of the CSC and the fuel price indicates the amount of cost-effective savings, totaling $1.9 \mathrm{GJ} / \mathrm{t}$ of steel.

When evaluation of productivity benefits in included in the CCE calculation, the CSC can change significantly. The authors of the report identified quantifiable productivity benefits for 14 of the 47 energy-efficiency measures. Table 5 lists these measures and the source of the productivity benefit. In electric steelmaking, three of the common benefits are reduced tap-to-tap time, which means that more steel can be produced by a furnace in a given time, reduced electrode consumption and reduced refractory wear, which both save maintenance and replacement costs. In integrated steelmaking, the injection of coal or natural gas in the blast furnace means less coke is needed, so maintenance and production costs associated with cokemaking are reduced. Measures that improve the casting or rolling of steel can benefits both types of steelmaking by lowering handling costs and material losses. 
Table 4. State-of-the-art-energy efficiency measures in the US iron and steel industry

Overall measures (Measures apply to both integrated and secondary plants unless otherwise specified)

Preventive maintenance

Energy monitoring and management systems

Variable speed drives for flue gas control, pumps, and fans (integrated only)

Cogeneration (integrated only)

Integrated steel making measures

Iron ore preparation (sintermaking)

- $\quad$ Sinter plant heat recovery

- $\quad$ Use of Waste fuels in the sinter plant

- Reduction of air leakage

- Increasing bed depth

- Improved process control

Coke making

- Coal moisture control

- $\quad$ Programmed heating

- Variable speed drive on coke oven gas compressors

- $\quad$ Coke dry quenching

Iron making-blast furnace

- $\quad$ Pulverized coal injection (medium and high levels)

- Injection of natural gas

- $\quad$ Top pressure recovery turbines (wet type) Recovery of blast furnace gas

- Hot blast stove automation

- $\quad$ Recuperator on the hot blast stove

- Improved blast furnace control

Steel making-basic oxygen furnace

- $\quad$ BOF gas \& sensible heat recovery (suppressed combustion)

- $\quad$ Variable speed on drive on ventilation fans

Casting and rolling (measures apply to integrated and secondary plants unless otherwise specified Rolling

- $\quad$ Hot charging (integrated only)

- $\quad$ Recuperative burners in the reheating furnace

- $\quad$ Process control in the hot strip mill

- Insulation of furnaces

- $\quad$ Energy efficient drives in the hot rolling mill

- Heat recovery on the annealing line (integrated only)

- Waste heat recovery from cooling water

- $\quad$ Controlling oxygen levels and variable speed drives on combustion air fans

- $\quad$ Automated monitoring \& targeting system (integrated only)

- $\quad$ Reduced steam use in the pickling line (integrated only)

\section{Secondary steel making measures}

Electric arc furnace

- Improved process control (neural networks)

- $\quad$ Flue gas monitoring

- $\quad$ Flu gas monitoring and control

- Bottom stirring/gas injection

- $\quad$ Foamy slag practices

- $\quad$ Oxy-fuel burners/lancing

- $\quad$ Eccentric bottom tapping (EBT)

- $\quad$ Direct current (DC) arc furnaces

Scrap preheating

- $\quad$ FUCHS shaft furnace

- $\quad$ Twin shell DC arc furnace
- $\quad$ Consteel process
Casting

- $\quad$ Adopt continuous casting (integrated only)

- $\quad$ Efficient ladle preheating

- $\quad$ Thin slab casting 
Table 5. Fourteen efficiency measures in the iron and steel industry that include productivity benefits

\begin{tabular}{|c|c|c|}
\hline Energy efficiency measure & Productivity benefit & $\begin{array}{l}\text { Cost savings } \\
\text { (US\$/tonn } \\
\text { e steel) }\end{array}$ \\
\hline \multicolumn{3}{|l|}{ Electric steelmaking } \\
\hline Oxy-fuel burners & Reduces tap-to-tap times & $\$ 1.00$ \\
\hline $\begin{array}{l}\text { Scrap preheater-FUCHS shaft } \\
\text { furnace }\end{array}$ & $\begin{array}{l}\text { Reduces electrode consumption: } \\
\text { improves yield; } \\
\text { saves waste handling costs } \\
\end{array}$ & $\$ 0.80$ \\
\hline $\begin{array}{l}\text { Bottom stirring-stirring gas } \\
\text { injection }\end{array}$ & $\begin{array}{l}\text { Improves yield; } \\
\text { cuts need for inert gas purchases }\end{array}$ & $\$ 0.22$ \\
\hline Improved process control & $\begin{array}{l}\text { Reduces electrode consumption; } \\
\text { improves yield; } \\
\text { saves maintenance costs }\end{array}$ & $\$ 0.90$ \\
\hline DC-arc furnace & $\begin{array}{l}\text { Reduces electrode consumption; } \\
\text { reduces tap-to-tap time }\end{array}$ & $\$ 0.13$ \\
\hline Scrap preheater-CON-STEEL & Reduces electrode consumption; improves yield & $\$ 0.38$ \\
\hline Scrap preheater-twin shell & Reduces tap-to-tap time & $\$ 0.11$ \\
\hline Foamy slag & Reduces tap-to-tap time & $\$ 0.63$ \\
\hline \multicolumn{3}{|l|}{ Integrated Steelmaking } \\
\hline Injection of NG--140kg/thm & $\begin{array}{l}\text { Decreases coke use: } \\
\text { O\&M and material cost savings at the coke } \\
\text { battery }\end{array}$ & $\$ 0.36$ \\
\hline $\begin{array}{l}\text { Pulverized coal injection-130 } \\
\text { kg/thm }\end{array}$ & $\begin{array}{l}\text { Decreases coke use: } \\
\text { O\&M and material cost savings at the coke } \\
\text { battery }\end{array}$ & $\$ 1.43$ \\
\hline $\begin{array}{l}\text { Pulverized coal injection-225 } \\
\text { kg/thm }\end{array}$ & $\begin{array}{l}\text { Decreases coke use: } \\
\text { O\&M and material cost savings at the coke } \\
\text { battery }\end{array}$ & $\$ 0.27$ \\
\hline Adopt continuous casting & $\begin{array}{l}\text { Saves equipment/handling costs; } \\
\text { reduces material losses }\end{array}$ & $\$ 5.36$ \\
\hline Hot charging & $\begin{array}{l}\text { Reduces material losses; } \\
\text { improves productivity }\end{array}$ & $\$ 0.25$ \\
\hline \multicolumn{3}{|l|}{ Both electric and integrated } \\
\hline Thin slab casting & $\begin{array}{l}\text { Improves productivity; } \\
\text { reduces material losses }\end{array}$ & $\$ 6.27$ \\
\hline
\end{tabular}

When these productivity benefits are quantified and included in the cost-effectiveness calculations, the evaluations and the CSC look very different. In Table 6, each of the 14 measures with productivity benefits are evaluated with and without the benefits included. The table shows the CCE in each case, how each measure ranked out of the 47 total measures (where 1 is the most cost-effective), and whether the measure is cost-effective when compared to the average primary energy price in the sector. The CCEs of these measures change significantly when the productivity benefits are included. 
Table 6. The effect of productivity benefits on the cost-effectiveness of iron and steel conservation measures

\begin{tabular}{|c|c|c|c|c|c|c|}
\hline \multirow[b]{2}{*}{ Measure } & \multicolumn{3}{|c|}{ Without productivity benefit } & \multicolumn{3}{|c|}{ Including productivity benefit } \\
\hline & $\begin{array}{c}\text { CCE } \\
(\$ / G J)\end{array}$ & $\begin{array}{l}\text { Rank (of } \\
\text { 47) }\end{array}$ & $\begin{array}{r}\text { Cost- } \\
\text { effective? }\end{array}$ & $\begin{array}{c}\text { CCE } \\
(\$ / G J)\end{array}$ & $\begin{array}{l}\text { Rank (of } \\
\text { 47) }\end{array}$ & $\begin{array}{r}\text { Cost- } \\
\text { effective? }\end{array}$ \\
\hline $140^{\text {Inj. of NG- }}$ & 3.1 & 19 & NO & -0.5 & 8 & YES \\
\hline Coal inj.-225 & 3.9 & 22 & NO & 1.0 & 23 & YES \\
\hline Coal inj.-130 & 4.4 & 23 & NO & 0.1 & 11 & YES \\
\hline $\begin{array}{l}\text { DC-arc } \\
\text { furnace }\end{array}$ & 5.0 & 26 & NO & -1.3 & 6 & YES \\
\hline $\begin{array}{l}\text { Process } \\
\text { control }\end{array}$ & 5.6 & 27 & NO & -2.1 & 5 & YES \\
\hline $\begin{array}{r}\text { Scrap } \\
\text { preheating }\end{array}$ & 6.7 & 31 & NO & -0.6 & 7 & YES \\
\hline $\begin{array}{l}\text { Thin slab } \\
\text { casting }\end{array}$ & 8.5 & 35 & NO & 1.9 & 27 & YES \\
\hline Hot charging & 8.9 & 36 & NO & 5.3 & 35 & NO \\
\hline $\begin{array}{l}\text { FUCHS } \\
\text { furnace }\end{array}$ & 12.7 & 37 & NO & -3.5 & 3 & YES \\
\hline $\begin{array}{l}\text { Adopt cont. } \\
\text { cast }\end{array}$ & 14.3 & 39 & NO & -3.5 & 2 & YES \\
\hline Twin shell & 16.6 & 40 & NO & 3.3 & 30 & NO \\
\hline $\begin{array}{l}\text { Oxy-fuel } \\
\text { burners }\end{array}$ & 17.4 & 41 & NO & -5.5 & 1 & YES \\
\hline $\begin{array}{l}\text { Bottom } \\
\text { stirring }\end{array}$ & 20.5 & 45 & NO & -2.4 & 4 & YES \\
\hline Foamy slag & 30.1 & 46 & NO & 7.2 & 40 & NO \\
\hline
\end{tabular}

Re-evaluating the measures as shown in Table 6 results in a very different CSC for the iron and steel industry, shown in Fig. 2.Many of the measures having high CCE without productivity benefits have much lower costs with the benefits, so their position in the curve moves toward the $\mathrm{x}$-axis. In general, this shifts the CSC downwards. The point at which the CSC meets the price of energy (giving the total cost-effective savings) will move further away from the $y$-axis. While the total technical potential for primary energy savings remains the same, $5.9 \mathrm{GJ} / \mathrm{t}$ of steel produced, the potential for cost-effective savings has doubled to $3.8 \mathrm{GJ} / \mathrm{t}$. Fig. 2 shows both the CSCs, one accounting for productivity benefits and one not. The higher cost options are cut off the top of this figure to show the detail of measures close to the average energy prices. 


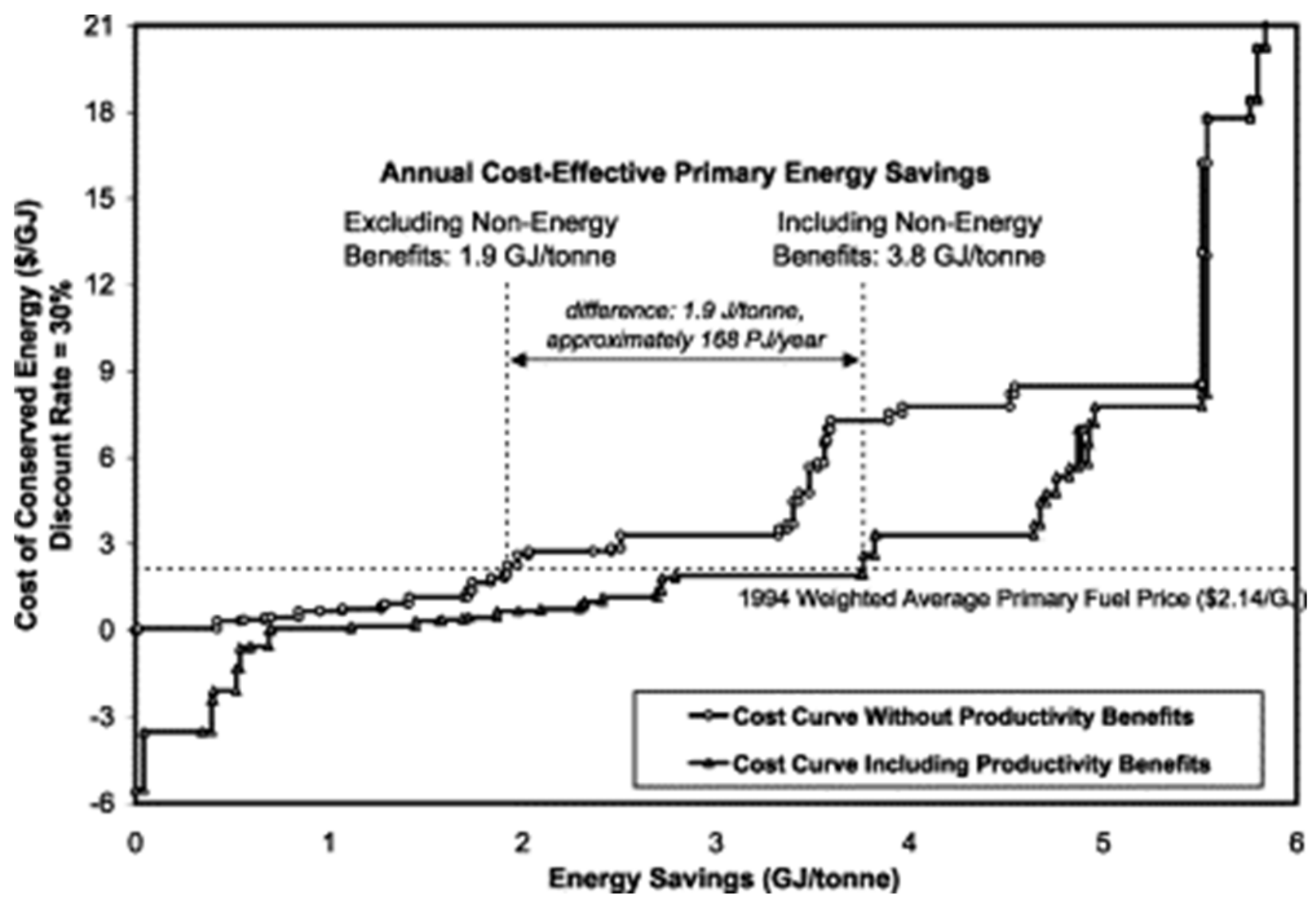

Fig. 2. Conservation supply curves for the iron and steel industry without productivity benefits and including productivity benefits.

\section{Discussion}

Including productivity benefits in the evaluation of energy-efficiency measures leads to a more accurate understanding of cost-effective energy savings potential across an industry. However, there are both limitations and complicating factors, that make the assessment of these productivity benefits and their incorporation into a quantitative analytical framework difficult. Special attention should be paid to how these complications are addressed to assure the robust nature of the analysis.

One complication is the uncertainty in evaluating certain productivity benefits. Within the cost curve methodology, it is necessary to evaluate the monetary value of all productivity benefits, but not all these benefits are easily quantified in financial terms. For example, improved working environments that lead to greater safety and employee satisfaction may very well enhance the productivity of the firm, but any quantifiable correlation will be difficult. Reduced emissions of criteria pollutants are another important benefit that often accompanies energy efficiency, but the value of this benefit will depend on the regulatory issues based on the location of individual plants.

The fact that much of the information on productivity benefits is derived only from case studies of individual projects underscores a potentially serious limitation as we previously noted - the lack of both time series and plant level data on the appropriate mix of inputs by which we might more accurately assess the productivity impacts resulting from a changing pattern of investments and energy consumption. While the energy performance of a piece of efficient equipment may be extensively tested and even guaranteed by the manufacturer, the 
reported productivity benefits are generally observations from one or more facilities. It is reasonable to expect variation between plants in the benefits observed. Many of the benefits are not just a function of the efficiency measure, but also of site-specific factors, such as the scale of the project, the maintenance schedule of the facility, and the capacity at which the equipment is operated. As shown in the analysis of the case studies' productivity improvements are often not reported, and even if they are, they are most often not quantified. Reporting and accounting for the productivity benefits will not only improve the likelihood of project implementation, but is also needed in the assessment of energy efficiency potentials. Improved reporting and accounting of productivity benefits is needed in order to improve the usefulness of project descriptions and databases. Moreover, the development of meaningful time series data, whether at the plant or sector level, would increase confidence in the results of such assessments.

A third complication in assessing productivity benefits is that there may also be negative impacts associated with energy efficiency measures that will offset some of the benefits. These impacts may be just as difficult to quantify as productivity benefits. One potential offset to the benefits of an energy-efficiency measure is that if it involves new technology, there will be some risk in making the investment. Firms may need to train personnel to use the new equipment, and may have difficulty maintaining or repairing the equipment. Additionally, a new project may require a shutdown of production during implementation, leading to production losses. Since these negative impacts will certainly play a role in the decision making of the investor at the firm level, they should be included in the assessment of total energy conservation potential.

In the face of these complications it is important to use a standard framework for analyzing productivity benefits for energy-efficiency projects, such as the one described in the methodology section of this paper. By following this framework, the cost evaluation of productivity benefits is formalized and transparent. Since the evaluation of productivity benefits is not always unambiguous, the transparency of this evaluation framework is important both to give credibility to calculation and to provide flexibility to a user looking to apply the CSC framework to another scenario.

\section{Conclusion}

All analyses of how industries make decisions about technology return to the basic principle of 'the bottom line', i.e. how will this technology affect the production costs of the firm. This is true when making decisions about a project at an individual facility or when assessing trends across an industry. The interaction of new technologies and production costs must be understood in order to make realistic forecasts of industrial behavior. For new energy-efficient technologies, one primary effect on cost analysis may be a reduction in fuel expenses. At the same time, these technologies may introduce one or more productivity benefits that could lower the firm's production costs. Capturing the effect of these benefits on 'the bottom line' is important for assessing the likelihood of a technology's adoption and penetration and the impact this will have on energy use patterns.

As this study has shown, many industry decision-makers have already discovered the important benefits of energy efficiency technologies as a productivity investment. Although case studies reported here do not comprise a statistically valid sample, the data provide useful insights that might assist in the evaluation of energy technology investments. To achieve the full potential of such investments, however, it requires that the analytical tools used to evaluate such projects be significantly upgraded. In short, they need to incorporate methods, which better track both the energy and non-energy benefits of a given investment. 
In this paper we proposed a methodology for assessing productivity benefits of energy efficiency investments and incorporating them into assessments of energy saving potential across an industry. This approach begins with documenting the additional benefits associated with an energy-efficient technology and noting all of the assumptions needed to quantify this benefit in cost terms, if possible. These economic factors are then included in calculations of the cost of conserved energy (CCE) for the measures, and the CCEs are used to construct conservation supply curves (CSC). The CSCs indicate the potential for energy efficiency improvement across an industry or sector.

We have preliminarily tested this methodology using available data on energy-efficiency options in the US iron and steel industry. To illustrate the importance of including productivity benefits we constructed CSCs with and without the inclusion of productivity benefits that had been identified for 14 energy efficiency options in a previous study. These two curves show how productivity benefits can change the shape and placement of the CSC. For the iron and steel sector, removing the productivity benefits from the cost calculations cut the potential for energy savings in half, from $3.8 \mathrm{GJ} / \mathrm{t}$ of steel to $1.9 \mathrm{GJ}$. This difference amounts to nearly $170 \mathrm{PJ}$ of potential energy savings per year for the entire sector.

While including these productivity benefits is important, and conservation supply curves provide an effective means for including them in an analysis, estimating the magnitude of these benefits can be difficult. When the benefit identified has a direct relationship to the production process, quantifying changes in productivity can be straightforward. When the benefit is not easily quantified, such as improved working conditions, or not linked to productivity, such as lower emission of criteria pollutants, assumptions will be needed to translate the benefit into a comparable cost figure. When quantified benefits are available for a given efficiency measure, the values often come from a published case study, or limited number of observations, so the robustness of the value is uncertain. Also, there is the potential for negative cost impacts to play a role in the cost evaluation of a project. These impacts should also be assessed. In general, using a transparent framework that documents the productivity benefits and the assumptions needed to translate them into useful cost figures, leads to a more credible evaluation. The collection of appropriate sector or plant level data over time would increase the confidence in the results of future assessments.

\section{Acknowledgements}

This work was supported by the Office of Atmospheric Programs of the U.S. Environmental Protection Agency, through the U.S. Department of Energy under Contract No. DE-AC0376SF00098. Any mistakes remain the responsibility of the authors. The views expressed in this paper do not necessarily reflect those of the U.S. Environmental Protection Agency, the U.S. Department of Energy, or the U.S. Government.

\section{References}

1. Mills E, Rosenfeld A. Consumer non-energy benefits as a motivation for making energyefficiency improvements. In: Proceedings ACEEE 1994 Summer Study on Energy Efficiency in Buildings. Washington, DC: American Council for an Energy Efficient Economy; 1994;4:201-14.

2. G.A. Boyd and J.X. Pang, Estimating the linkage between energy efficiency and productivity. Energy Policy 285 (2000), pp. 289-296.

3. H.C. Kelly, P.D. Blair and J.H. Gibbons, Energy use and productivity: current trends and policy implications. Ann. Rev. Energy 14 (1989), pp. 321-352. 
4. US Department of Energy. The interrelationship between environmental goals, productivity improvement, and increased energy efficiency in integrated paper and steel plants. DOE/PO0055. Washington, DC: US Department of Energy, Office of Policy and International Affairs and Office of Energy Efficiency and Renewable Energy, 1997.

5. M. Pye and A. McKane, Enhancing shareholder value: making a more compelling energy efficiency case to industry by quantifying on-energy benefits. In: Proceedings 1999 Summer Study on Energy Efficiency in Industry, , American Council for an Energy-Efficient Economy, Washington DC (1999), pp. 325-336.

6.P. Lilly and D. Pearson, Determining the full value of industrial efficiency programs. In: Proceedings 1999 Summer Study on Energy Efficiency in Industry, , American Council for an Energy-Efficient Economy, Washington DC (1999), pp. 349-362.

7. R.N. Elliott, J.A. Laitner and M. Pye, Considerations in the estimation of costs and benefits of industrial energy efficiency projects. , American Council for an Energy Efficient Economy, Washington DC (1997).

8.M. Pye, Making business sense of energy efficiency and pollution prevention. , American Council for an Energy Efficient Economy, Washington DC (1998).

9. CADDET Register. Centre for the Analysis and Dissemination of Demonstrated Energy Technologies (CADDET). Sittard, The Netherlands: CADDET, 2000. The complete database is available through the CADDET web site at http://www.caddet-ee.org.

10. US Department of Energy. Climate wise case study compendium: report 1, US Department of Energy, Office of Industrial Technologies, Golden, CO: National Renewable Energy Laboratory, 1997.

11. J.E. Quinn and J.E. Reed, Economic, and environmental impacts of advanced industrial process innovations, 1976-1996. In: Proceedings 1997 ACEEE Summer Study on Energy Efficiency in Industry, , American Council for an Energy Efficient Economy, Washington DC (1997), pp. 417-428.

12. J.L. Pellegrino and J.E. Reed, Energy, economic, and environmental impacts of advanced technology in the process industries. In: Proceedings 1997 ACEEE Summer Study on Energy Efficiency in Industry, , American Council for an Energy Efficient Economy, Washington DC (1997), pp. 323-334.

13. I.A. Chisti, Energy, productivity, and economic implications of resource and environmental policy in Southern California. In: Proceedings ACEEE 1994 Summer Study on Energy Efficiency in Buildings, vol 4, , American Council for an Energy Efficient Economy, Washington DC (1994), pp. 49-56.

14. J.J. Romm, Lean and clean management: how to boost profits and productivity by reducing pollution. , Kodansha America, New York, NY (1994).

15. J.J. Romm, Cool companies: how the best businesses boost profits and productivity by cutting greenhouse gas emissions. , Island Press, New York, NY (1999).

16. A.E. Ingram, Recognizing and defining the productivity gains as part of electrical DSM installations in the paper industry. In: Proceedings 1995 Summer Study on Energy Efficiency in Industry, , American Council for an Energy-Efficient Economy, Washington DC (1995), pp. 205-214.

17. Ross MH, Thimmapuram P, Fisher RE, Maciorowski W. Long-term industrial energy forecasting (LIEF) model (18-sector version). Argonne, IL: Argonne National Laboratory. 
18. US Department of Energy, Industrial sector demand module of the national energy modeling system (DOE/EIA-M064(97)). , US Department of Energy, Washington, DC (1997).

19. Nyboer J, Bailie A, Fogwill A, Liu H, Oliver J, Willis P. Industrial energy end-use analysis and conservation potential in six major industries in Canada. Prepared for Natural Resources Canada. Vancouver, BC: M.K. Jaccard and Assoc., Willis Energy Services Ltd, 1997.

20. D.J. Gielen, Technology characterisation for ceramic and inorganic materials, input data for Western European MARKAL. , Netherlands Energy Research Foundation, Petten, The Netherlands (1997).

21. J.R. Ybema, P. Lako, D.J. Gielen, R.J. Oosterheert and T. Kram. Prospects for energy technologies in The Netherlands vols. 1 and 2, Netherlands Energy Research Foundation, Petten, The Netherlands (1995).

22. J.G. De Beer, E. Worrell and K. Blok, Sectoral potentials for energy efficiency improvements in The Netherlands. Int J Global Energy Issues 8 5-6 (1996), pp. 476-491.

23. E. Jochem and H. Bradke, Energieeffizienz, Strukturwandel und Produktionsentwicklung der Deutschen Industrie. , Forschungszentrum Juelich, Juelich, Germany (1996).

24. M. Bernstein, R. Lempert, D. Loughran and D. Ortiz, The public benefit of California's investments in energy efficiency. , RAND Corporation, Santa Monica, CA (2000).

25. E. Worrell, N. Martin and L. Price, Energy efficiency and carbon dioxide emissions reduction opportunities in the U.S. iron and steel sector. Energy 265 (2001), pp. 513-536.

\section{End notes}

1 Other approaches referred to as 'top-down' rely on macro-economic quantities and parameterized trends in order to describe industrial behavior. For example, the LIEF model ${ }^{\text {[17] }}$ uses top-down conservation supply curves in which the energy savings are related to energy price changes through econometrically-estimated elasticity parameters.

\section{SCLAI MER}

This document was prepared as an account of work sponsored by the United States Government. While this document is believed to contain correct information, neither the United States Government nor any agency thereof, nor The Regents of the University of California, nor any of their employees, makes any warranty, express or implied, or assumes any legal responsibility for the accuracy, completeness, or usefulness of any information, apparatus, product, or process disclosed, or represents that its use would not infringe privately owned rights. Reference herein to any specific commercial product, process, or service by its trade name, trademark, manufacturer, or otherwise, does not necessarily constitute or imply its endorsement, recommendation, or favoring by the United States Government or any agency thereof, or The Regents of the University of California. The views and opinions of authors expressed herein do not necessarily state or reflect those of the United States Government or any agency thereof or The Regents of the University of California. 